\title{
Pengaruh Literasi Keungan Terhadap Kinerja UMKM Bordir Tasikmalaya
}

\author{
Ati Rosliyati \\ Pascasarjana Universitas Siliwangi \\ ati.rosliyati@unsil.ac.id \\ Yusup Iskandar \\ Fakultas Ekonomi Universitas Galuh \\ yusup.lio69@yahoo.com
}

\begin{abstract}
Abstrak Pentingnya literasi keuangan dikarenakan permasalahan literasi keuangan masih banyak di temukan di lapangan. Hal ini mendorong peneliti untuk melakukan penelitian dengan judul pengaruh literasi keuangan terhadap kinerja UMKM Bordir di Kota Tasikmalaya. Rancangan penelitian menggunakan penelitian kuantitatif dengan menggunakan pendekatan asosiatif. Penelitian kuantitatif adalah penelitian yang mengambil data berupa angka yang diolah secara statistik. Sampel penelitian ini adalah jumlah UMKM Bordir di Tasikmalaya yang terdaftar di Dinas Koperasi, Usaha Mikro, Kecil Dan Menengah, Perindustrian Dan Perdagangan yang berjumlah 9 UMKM. Penelitian ini dilaksanakan pada bulan Juli 2021 dengan instrumen penelitian berupa angket kinerja dan literasi keuangan. Berdasarkan hasil pengolahan dan analisis data maka dapat disimpulkan bahwa literasi keuangan memiliki pengaruh yang signifikan dalam pengelolaan keuangan UMKM yang berdampak kepada kinerja UMKM Bordir di Kota Tasikmalaya
\end{abstract}

\section{Kata Kunci literasi keuangan, Kinerja UMKM}

\section{PENDAHULUAN}

Pelaksanaan edukasi kepada masyarakat mengenai pengelolaan keuangan perlu diberikan kepada organisasi ataupun perorangan agar dapat mengelola keuangannya dengan baik (Yushita, 2017). Usaha Mikro Kecil dan Menengah (UMKM) menjadi lembaga yang perlu mendapatkan edukasi mengenai pengelolaan keuangan yang baik. UMKM memiliki peranan penting dikarenakan jumlahm UMKM di Indonesia termasuk yang tinggi dan merupakan kelompok usaha yang tahan terhadap goncangan krisis ekonomi, terlebih pada saat pandemic covid-19 kali ini. Populasi UMKM di Indonesia menurut data adalah 98,7\% usaha mikro, sisanya adalah usaha kecil dan menengah (UKM, 2018)

Pentingnya literasi keuangan dikarenakan permasalahan literasi keuangan masih banyak di temukan di lapangan. Hal ini berdasarkan hasil survei Nasional Literasi Keuangan dan Inklusi Nasional Keuangan (SNLIK) tahun 2019 yang dilakukan oleh Otoritas Jasa Keuangan (OJK) menyatakan bahwa Indeks Literasi Keuangan di Indonesia mengalami peningkatan menjadi $38,03 \%$ dari sebelumnya yaitu $29,66 \%$ pada tahun 2016. Artinya berdasarkan data tersebut menunjukkan hanya 38,03\% masyarakat Indonesia yang memiliki literasi keuangan yang baik. Sementara untuk indeks inklusi keuangan 2019 
mencapai 76,19\% yang meningkat dibandingkan dengan hasil survei pada tahun 2016 yang hanya sebesar 67,8\%. Namun khusus pada sektor UMKM, Menurut hasil Survei Nasional Literasi Keuangan (SNLK) yang dilakukan OJK tahun 2016 tingkat literasi keuangan pada kelompok UMKM hanya sebesar $15,68 \%$. Hal tersebut mencerminkan masih rendahnya pengetahuan mengenai literasi keuangan di kalangan pemilik UMKM.

Literasi keuangan pada dasarnya merupakan kebutuhan dasar bagi setiap orang atau organisasi sekalipun (Cole \& Fernando, 2008; Patrisia \& Fauziah, 2019; Xiao et al., 2014). Hal ini dikarenakan untuk dapat mengelola keuangan yang baik diperlukan pengelolaan keuangan yang baik (Idawati \& Pratama, 2020; Saskia \& Yulhendri, 2020; Yushita, 2017). Literasi keuangan merupakan kecakapan seseorang dalam merencanakan dan melakukan pengelolaan terhadap keuangannya, hal ini bertujuan agar setiap orang mampu hidup sejahtera dan dari segi organisasi, literasi keuangan digunakan agar menjadi organisasi yang tidak memiliki masalah dengan pengelolaan keuangannya. Literasi keuangan bagi pemilik usaha juga dapat mengurangi risiko dalam diversifikasi asset serta pengelolaan utang perusahaan. Oleh karena itu, orang dengan literasi keuangan yang baik dia memiliki pengetahuan, keterampilan serta keyakinan dalam pengambilan keputusan untuk pengelolaan keuangannya (Herawati, 2015; Margaretha \& Pambudhi, 2015; Sayinzoga et al., 2016; Susanti et al., 2018). Beberapa hal yang menjadi perhatian dalam literasi keuangan adalah pengelolaan keuangan dasar, pengelolaan keuangan simpanan, asuransi sampai dengan inverstasi.

Melihat pentingnya literasi keuangan sudah pasti bahwa UMKM perlu mendapat pemahaman mengenai literasi keuangan agar mampu mengelola keuangan dengan baik (Amaliyah \& Witiastuti, 2015; Laily, 2016; Saskia \& Yulhendri, 2020). Tanpa literasi keuangan yang baik maka UMKM tersebut tidak mampu mengambil keputusan pengelolaan yang tepat sesuai dengan kondisi keuangan yang dimiliki UMKM tersebut. Salah satu UMKM di Tasikmalaya yang bergerak dalam bidang bordir adalah UMKM Dawalul Bordir. UMKM Dawalul merupakan UMKM yang sudah lama berdiri dalam bidang Bordir di Kota Tasikmalaya. Pengelolaan keuangan sudah dilakukan dengan mekanisme yang digunakan dengan pengetahuan dasar dari pemilik UMKM tersebut, dan tidak mengetahui detail mengenai pengelolaan keuangan yang baik.

Pengelolaan keuangan menjadi suatu masalah UMKM karena pemilik UMKM terhadap pengelolaan keuangan yang benar sesuai dengan kaidah-kaidah standar akuntansi yang berlaku (Djou, 2019; Putri, 2020; Sabilla \& Wijayangka, 2019). Hal ini biasanya muncul karena keterbatasan pengetahuan pengelola UMKM mengenai informasi pengelolaan keuangan sesuai dengan standar akuntansi yang baik. Pengelolaan keuangan menjadi salah satu aspek penting bagi kemajuan perusahaan. Pengelolaan keuangan dapat dilakukan melalui akuntansi. Akuntansi merupakan proses sistematis untuk menghasilkan informasi keuangan yang dapat digunakan untuk pengambilan keputusan bagi penggunanya. Sepanjang Usaha Mikro Kecil Menengah (UMKM) masih menggunakan uang sebagai alat tukarnya, akuntansi sangat dibutuhkan oleh UMKM tersebut.

Pengelolaan keuangan yang baik tentu akan berakibat terhadap kinerja Dwitya (2016) mengatakan bahwa kinerja UMKM dianalisis dengan menggunakan pendekatan yang didasarkan pada tiga asumsi, yaitu: 1). Pengukuran kinerja UMKM kerap sulit dilakukan secara kuantitatif, dikarenakan terbatasnya sumber daya (pemahaman keuangan dan tenaga kerja). 2). Pengukuran kinerja pada umumnya melihat indikator keuangan yang 
kompleks, sehingga hal ini tidak secara lengkap memperlihatkan kondisi aktual yang terjadi di bisnis tersebut. 3). Pengukuran kinerja yang kerap dipakai relatif hanya sesuai bila digunakan untuk perusahaan besar yang ter-struktur dalam manajemen perusahaannya. Dari hal tersebut maka digunakan pendekatan non cost performance measures yaitu pengukuran melalaui persepsi untuk mengukur tingkat kinerja UMKM, baik kinerja keuangan maupun non keuangan

Melihat uraian pentingnya literasi keuangan bagi UMKM maka peneliti melakukan penelitian mengenai literasi keuangan yang dihubungkan dengan kinerja pada UMKM Bordir di Tasikmalaya. Hal ini didasarkan pada penelitian (Djou, 2019; Saskia \& Yulhendri, 2020; Yanti, 2019), memperlihatkan hasil penelitian bahwa literasi keuangan yang baik berpengaruh terhadap pengelolaan keuangan dan dampaknya terhadap kinerja UMKM.

\section{METODOLOGI PENELITIAN}

Rancangan penelitian menggunakan penelitian kuantitatif dengan menggunakan pendekatan asosiatif. Penelitian kuantitatif adalah penelitian yang mengambil data berupa angka yang diolah secara statistik. Variabel yang diteliti adalah mengenai literasi keuangan, dan kinerja UMKM. Literasi keuangan sebagai variabel bebas dan kinerja UMKM bertindak sebagai variabel terikat. Sampel penelitian ini adalah jumlah UMKM Bordir di Tasikmalaya yang terdaftar di Dinas Koperasi, Usaha Mikro, Kecil Dan Menengah, Perindustrian Dan Perdagangan yang berjumlah 9 UMKM. Penelitian ini dilaksanakan pada bulan Juli 2021. Desain penelitian dapat tergambarkan sebagai berikut: Literasi Keuangan $\rightarrow$ Kinerja UMKM

$\mathrm{X}$

$\mathrm{Y}$

Teknik pengumpalan data dilakukan dengan cara memberikan angket yang berisis mengenai literasi keuangan dan Kinerja UMKM. Pengambilan data menjadi penting karena menentukan keberhasilan dalam pengolahan dan analisis data tersebut. Teknik analisis data menggunakan teknik regresi linier sederhana dengan mencari pengaruh literasi keuangan terhadap kinerja UMKM tersebut. Analisis prasyarat dilakukan agar memenuhi kriteria uji regresi yang benar.

\section{HASIL PENELITIAN}

Hasil penelitian mengenai pengaruh literasi keuangan terhadap kinerja pegawai merupakan bagian inti dari penelitian ini. Indikator literasi keuangan yang diambil adalah pengetahuan umum mengenai pengelolaan keuangan, tabungan dan pinjaman, asuransi dan investasi, sedangkan kinerja UMKM yang diukur adalah pertumbuhan usaha, total pendapatan usaha, total order dan posisi kas usaha.

Statistika deskriptif mengenai literasi keuangan dapat tergambarkan sebagai berikut:

Tabel 1 Statistika Deskriptif

Literasi Keuangan Kinerja UMKM




\begin{tabular}{ccc}
\hline Rata-rata & 78,34 & 72,25 \\
\hline Maksimum & 90 & 80 \\
\hline Minimum & 65 & 63 \\
\hline Kriteria & Baik & Baik \\
\hline
\end{tabular}

Hasil tersebut menunjukan bahwa literasi keuangan UMKM Bordir di Tasikmalaya sudah berada pada katgori baik, namun demikian perlu ditingkatkan pada aspek pengelolaan dasar keuangan karena dari 9 UMKM yang menjadi sampel penelitian, hampir $50 \%$ pengelolaannya masih menggunakan sistem manual yang dilakukan secara turun temurun dari keluarga, kemudian kinerja UMKM berkriteria baik, namun demikian berdasarkan hasil observasi dilapangan beberapa mengalami kinerja UMKM yang menurun terutama pada saat COvid-19 yang berakibat terhadap volume penjualan yang menurun. Namun demikian perlahan-lahan masih bisa naik dikarenakan covid-19 mulai melandai dan pembatasan sudah mulai dikurangi sehingga hasil dari bordir Tasikmalaya sudah bisa dikirim ke kota kota besar terutama Jakarta.

Analisis data dilanjutkan dengan uji prasyarat, yaitu uji normalitas data antara literasi keuangan dan kinerja UMKM. Uji normalitas menggunakan uji Shapiro wilk, dengan ketentuan jika nilai signifikansi >0,05 maka distribusi data normal, dan sebaliknya jika < 0,05 maka distribusi data tidak normal. Hasil dari uji normalitas adalah sebagai berikut:

Tabel 2 Uji Normalitas

Tests of Normality

\begin{tabular}{l|r|r}
\hline & \multicolumn{2}{|c}{ Shapiro-Wilk } \\
\hline & \multicolumn{1}{|c}{ Sig. } & Kesimpulan \\
\hline Literasi Keunagan & .435 & Distribusi data Normal \\
\hline Kinerja UMKM & .166 & Distribusi data Normal \\
\hline
\end{tabular}

Hasil tersebut memberikan gambaran bahwa nilai signifikansi untuk literasi keuangan dan kinerja UMKM > 0,05 dengan demikian semua data memiliki sebaran yang berdistribusi normal, kemudian penelitian dilanjutkan dengan melakukan uji linieritas untuk melihat linieritas antara variabel. Hasilnya adalah sebagai Berikut:

Tabel 3 Uji Linieritas

\begin{tabular}{lcr}
\hline & \multicolumn{2}{c}{ Uji Linieritas } \\
\hline & Sig. & \multicolumn{2}{c}{ Kesimpulan } \\
\hline Literasi Keunagan $->$ & .003 & Linier \\
Kinerja UMKM & & \\
\hline
\end{tabular}

Melihat uji normalitas dan uji linieritas terpenuhi, maka dilanjutkan dengan uji regresi linier sederhana. 


\begin{tabular}{|c|c|c|c|c|c|c|}
\hline \multicolumn{7}{|c|}{ Coefficients $^{\mathrm{a}}$} \\
\hline & & \multicolumn{2}{|c|}{$\begin{array}{l}\text { Unstandardized } \\
\text { Coefficients }\end{array}$} & \multirow{2}{*}{$\begin{array}{c}\text { Standardized } \\
\text { Coefficients }\end{array}$} & \multirow[b]{2}{*}{$\mathrm{t}$} & \multirow[b]{2}{*}{ Sig. } \\
\hline \multicolumn{2}{|c|}{ Model } & $\mathrm{B}$ & Std. Error & & & \\
\hline \multirow[t]{2}{*}{1} & (Constant) & 1.551 & 1.079 & & 1.437 & .006 \\
\hline & $\begin{array}{l}\text { Literasi } \\
\text { Keuangan }\end{array}$ & .808 & .176 & .799 & 4.601 & .001 \\
\hline \multicolumn{3}{|c|}{$\begin{array}{l}\text { a. Dependent Variable: Kinerja } \\
\text { UMKM }\end{array}$} & & & & \\
\hline
\end{tabular}

Berdasarkan hasil tersebut bahwa persemaan regresi adalah $\mathrm{Y}=1,551+0,808 \mathrm{X}$, Ini menunjukan bahwa pengaruh positif yang ditimbulkan literasi keuangan terhadap kinerja UMKM. Persamaan regresi menunjukan bahwa setiap kenaikan satu satuan literasi keuangan maka kinerja UMKM naik sebesar 0,808 , kemudian nilai koefisien korelasi adalah sebagai berikut:

Tabel 5 Koefisien Korelasi dan Determinasi

\begin{tabular}{|c|c|c|c|}
\hline Model & $\mathrm{R}$ & R Square & $\begin{array}{c}\text { Adjusted R } \\
\text { Square }\end{array}$ \\
\hline 1 & $.799^{a}$ & .638 & .608 \\
\hline
\end{tabular}

Nilai koefisien korelasi adalah 0,799 dengan nilai koefisien determinasi adalah 0,638 atau $63,8 \%$. Dengan demikian bahwa literasi keuangan berpengaruh sebesar 63,8\% terhadap kinerja UMKM. Sisanya di pengaruhi oleh faktor lain yang tidak diteliti di dalam penelitian ini.

Berdasarkan hasil tersebut bahwa terdapat pengaruh yang signifikan literasi keuangan terhadap kinerja UMKM Bordir di Kota Tasikmalaya. Literasi keuangan merupakan sesuatu yang mendasar dalam hal pengelolaan keuangan. Pengelolaan keuangan yang baik tentu menjadi utama karena akan berdampak pada siklus perusahaan termasuk dalam hal ini UMKM. Oleh karena itu penting bahwa literasi keuangan menjadi hal yang perlu diperhatikan dalam pengelolaan UMKM. Hal ini sesuai dengan pendapat Melihat pentingnya literasi keuangan sudah pasti bahwa UMKM perlu mendapat pemahaman mengenai literasi keuangan agar mampu mengelola keuangan dengan baik (Amaliyah \& Witiastuti, 2015; Laily, 2016; Saskia \& Yulhendri, 2020). Hasil penelitian ini juga memberikan arti bahwa UMKM yang belum dapat mengelola keuangannya dengan baik tentu harus didorong untuk mengelola keuangannya dengan baik dengan jalan memahami literasi keuangan yang benar. Perlu adanya pelatihan agar pengelola UMKM dapat mengelola keuangannya secara profesional dengan dasar-dasar akuntansi yang benar.

\section{KESIMPULAN}

Berdasarkan hasil pengolahan dan analisis data maka dapat disimpulkan bahwa literasi keuangan memiliki pengaruh yang signifikan dalam pengelolaan keuangan UMKM yang berdampak kepada kinerja UMKM Bordir di Kota Tasikmalaya. Implikasi dari penelitian ini adalah bahwa UMKM yang belum mengelola keuangan secara profesional perlu 
diberikan pelatihan dalam pengelolaan keuangan dengan cara bekerjasama dengan dinas atau intansi yang membawahi UMKM di Kota Tasikmalaya

\section{UCAPAN TERIMA KASIH}

Ucapan terimakasih kepada rektor Universitas Siliwangi dan Direktur Pascasarjana Universitas Siliwangi dan Rektor Universitas Galuh yang telah membantu dukungan moril dalam penyusunan artikel ini.

\section{DAFTAR PUSTAKA}

Otoritas Jasa Keuangan (OJK). (2019). Survei Nasional Literasi Keuangan dan Inklusi Nasional Keuangan (SNLIK) tahun 2019

UKM., K. K. D. (2018). Kementerian Koperasi dan Usaha Kecil dan Menengah Republik Indonesia. Www.Depkop.Go.Id. http://www.depkop.go.id/

Amaliyah, R., \& Witiastuti, R. S. (2015). Analisis Faktor Yang Mempengaruhi Tingkat Literasi Keuangan Di Kalangan Umkm Kota Tegal. Management Analysis Journal, 4(3), 252-257. https://doi.org/10.15294/maj.v4i3.8876

Cole, S., \& Fernando, N. (2008). Assessing the Importance of Financial Literacy. Education, 9(3), 1-8. http://www.adb.org/Documents/Periodicals/Microfinance/finance200803.pdf

Djou, L. G. (2019). Analisis pengaruh literasi keuangan, sikap keuangan dan kepribadian terhadap perilaku pengelolaan keuangan UMKM di Kabupaten Ende. Jurnal Magisma, 7(2), 1-12. http://jurnal.stiebankbpdjateng.ac.id

Herawati, N. T. (2015). Kontribusi Pembelajaran Di Perguruan Tinggi Dan Literasi Keuangan Terhadap Perilaku Keuangan Mahasiswa. Jurnal Pendidikan Dan Pengajaran, 48(1-3). https://doi.org/10.23887/jppundiksha.v48i1-3.6919

Idawati, I. A. A., \& Pratama, I. G. S. (2020). Pengaruh Literasi Keuangan Terhadap Kinerja dan Keberlangsungan UMKM di Kota Denpasar. Warmadewa Management and Business Journal (WMBJ), 2(1), 1-9. https://doi.org/10.22225/wmbj.2.1.1644.1-9

Laily, N. (2016). Pengaruh Literasi Keuangan Terhadap Perilaku Mahasiswa Dalam Mengelola Keuangan. Journal of Accounting and Business Education, 1(4). https://doi.org/10.26675/jabe.v1i4.6042

Margaretha, F., \& Pambudhi, R. A. (2015). Tingkat Literasi Keuangan Pada Mahasiswa S-1 Fakultas Ekonomi. Jurnal Manajemen Dan Kewirausahaan (Journal of Management and Entrepreneurship), 17(1), 76-85. https://doi.org/10.9744/jmk.17.1.76-85

Patrisia, D., \& Fauziah, M. (2019). The Effect of Financial Literacy and Financial Management Behavior on Retirement Confidence. BISNIS \\& BIROKRASI: Jurnal Ilmu Administrasi Dan Organisasi, 23(3), 4. https://doi.org/10.2991/piceeba-19.2019.90 
Putri, W. E. (2020). Pengaruh Literasi Keuangan terhadap Pengelolaan Keuangan UMKM di Kecamatan Medan Marelan. Jurnal Pembangunan Perkotaan, 8(1), 45-50.

Sabilla, S. O., \& Wijayangka, C. (2019). Pengaruh literasi keuangan terhadap pertumbuhan usaha pada UMKM. Jurnal Manajemen Dan Bisnis, 3(1), 145-152.

Saskia, D. H., \& Yulhendri. (2020). Pengaruh Tingkat Literasi Keuangan terhadap Pengelolaan Keuangan pada Pelaku UMKM. Jurnal EcoGen, 3(3), 365-374.

Sayinzoga, A., Bulte, E. H., \& Lensink, R. (2016). Financial Literacy and Financial Behaviour: Experimental Evidence from Rural Rwanda. Economic Journal, 126(594), 1571-1599. https://doi.org/10.1111/ecoj.12217

Susanti, A., Ismunawan, ., Pardi, ., \& Ardyan, E. (2018). Tingkat Pendidikan, Literasi Keuangan, dan Perencanaan Keuangan terhadap Perilaku Keuangan UMKM di Surakarta. Telaah Bisnis, 18(1). https://doi.org/10.35917/tb.v18i1.93

Xiao, J. J., Ahn, S. Y., Serido, J., \& Shim, S. (2014). Earlier financial literacy and later financial behaviour of college students. International Journal of Consumer Studies, 38(6), 593-601. https://doi.org/10.1111/ijcs.12122

Yanti, W. I. P. (2019). Pengaruh Inklusi Keuangan Dan Literasi Keuangan Terhadap Kinerja Umkm Di Kecamatan Moyo Utara. Jurnal Manajemen Dan Bisnis, 2(1), 1-10.

Yushita, A. N. (2017). Pentingnya Literasi Keuangan Bagi Pengelolaan Keuangan Pribadi. Nominal, Barometer Riset Akuntansi Dan Manajemen, 6(1). https://doi.org/10.21831/nominal.v6i1.14330 